\title{
Revirando o imaginário - arte contemporânea e psicanálise
}

Maria Cristina Poli

O lançamento do livro $O$ avesso do imaginário: arte contemporânea e psicanálise, de Tania Rivera, merece ser festejado por vários motivos. $\mathrm{O}$ primeiro deles deve-se ao tema e a forma de sua elaboração na escrita rigorosa de Tania. Além disso, merece destaque a belíssima edição da Cosac Naif que, nos últimos anos, vem nos presenteando com os melhores exemplares de livros sobre arte. Trabalho de quem conhece e respeita seu público, erudito e exigente, e sabe que o conteúdo é indiscernível da forma.

A relação entre arte e psicanálise - e mais particularmente ainda -, entre arte contemporânea e psicanálise merecia há tempos um livro à altura de sua relevância e densidade. Talvez ele ainda não tivesse sido escrito pelas inúmeras dificuldades que comporta: exige um autor que conheça bem ambos os campos e tenha erudição e estilo suficientes para apresentá-los e relacioná-los de modo ao mesmo tempo rigoroso e convidativo à leitura, isto é, sem ser maçante ou hermético. O livro em questão consegue essa proeza ao apresentar um tema árduo a um leitor que não precisa necessariamente ser especialista em um ou outro desses terrenos. E faz isso construindo um diálogo de alto nível com alguns dos maiores 


\section{RESENHA DE LIVROS}

expoentes da filosofia, da psicanálise e da arte. Tarefa para poucos, muito poucos, e que só podemos festejar que a autora não tenha recuado diante dela.

A composição múltipla da obra, dividida em quatro partes de três capítulos cada (com exceção da última parte, composta por quatro capítulos), não deixa de sobressair uma nítida linha de força que conduz à elaboração do texto. Os diversos ensaios, ao mesmo tempo que dialogam entre si, também constituem unidades temáticas que mereceriam ser exploradas com toda singularidade que exigem: o trabalho de um artista específico, a operação com algum termo/conceito da teoria psicanalítica etc. Nessa polifonia, a linha argumentativa comum concerne à subversão dos regimes ou sistemas de representação operada simultaneamente pela arte e pela psicanálise. É por esse fio condutor - enunciado no título mesmo do trabalho $O$ avesso do imaginário - que os campos em enlace merecem e precisam ser adjetivados. Pois não se trata de uma arte genérica que está em causa, nem de uma psicanálise qualquer, pois nem toda psicanálise é subversiva. É da arte contemporânea e da psicanálise de herança freudo-lacaniana que se trata no livro e da subversão operada pelos autores e artistas que se inscrevem nessa tradição.

Essa precisão é fundamental para também reconhecermos que a operação de enlace moebiano proposta por Rivera entre os dois campos - arte e psicanálise - se detém naquilo que eles têm de mais inovador e ao mesmo tempo (talvez por isso mesmo) menos compreendido e acessível ao senso comum. É muito habitual ouvirmos críticas fortes e até ridicularizadoras da arte contemporânea, por vezes inclusive de quem as conhece bastante bem. Também a psicanálise, sobretudo a lacaniana, já foi taxada de uma série de adjetivos nada honrosos até mesmo por seus colegas mais próximos (os psicanalistas de outras tendências). Esta aparente repulsa às duas formas de expressão pode ser entendida como efeito da operação subversiva que elas propõem, como reações de resistência ao desassossego que promovem. "O eu não é senhor em sua própria casa", repete Tania Rivera a partir de Freud. E isso é radical, não é de modo algum uma frase de efeito, é a base do mal-estar que situa o sujeito na contemporaneidade em sua despossessão absoluta. Sujeito esse justamente tematizado, apresentado e reinventado constantemente pela psicanálise lacaniana e pela arte contemporânea, não para lhe dar uma nova casa, mas pelo contrário para, a cada vez, a cada ato artístico, assim como a cada análise (ou ato analítico), desmoronar o princípio de casa (de enfatuação egoica, coisa de que nem analistas nem artistas estão livres) que no interstício se tenta reconstruir.

Na primeira parte do livro, acompanhamos a aproximação entre os campos da arte e da psicanálise por meio da problematização da noção de sujeito, sua diferenciação do eu da imagem especular e da representação clássica, relação estabelecida com base na noção de ato. Como na performance, objeto da análise do primeiro capítulo, o ato que constitui o sujeito (mesmo que evanescente, como a própria performance o é) é também um apelo ao outro. Ele só se completa no outro. 
Essa aproximação inicial entre os campos da arte contemporânea e da psicanálise segue recuperando o gesto original de Freud, leitor dos sonhos, que desmonta a imagem onírica em palavras e letras e indica, no cerne da sua elaboração, um ponto de crítica à representação - o umbigo do sonho. Tania Rivera indica neste ato freudiano um atravessamento da imagem enquanto mimeses e enquanto representação; ato que é simultaneamente operado pela arte e pela psicanálise.

$\mathrm{Na}$ segunda parte do livro, é o conceito de sublimação que aproxima os dois campos sem, no entanto, sobrepô-los. Como indica Rivera, a sublimação na psicanálise não é um conceito interpretativo do campo da arte - como alguns autores parecem supor. Ele aponta antes a relação necessária do sujeito com a cultura e, nesse sentido sim, é homólogo àquilo que o campo da arte realiza. Principalmente porque não se trata de uma relação na qual os termos implicados (sujeito e cultura) se tocam de modo pacífico. Pelo contrário - como a autora demonstra muito bem ao longo desses três ensaios que incluem os trabalhos de Hélio Oiticica, Lygia Clark e Cildo Meireles em sua subversão do espaço clássico em um espaço moebiano - sublimar é sinônimo de revirar a realidade, alterar as medidas do interno e externo ao sujeito, transitando entre fantasia e produção artistica na (re)constituição da realidade.

Os capítulos que compõem a terceira parte do livro se dedicam a pensar a incidência do tempo, e da crítica, nas mudanças operadas nos sistemas de representação. É a chamada crise moderna que é posta na berlinda, demonstrando as inúmeras nuances subjacentes à análise de autores como Benjamin, com seu conceito de aura e de "reprodutibilidade técnica", ou Mário Pedrosa e a "arte pósmoderna" ou a "antiarte". A psicanálise também é produto do seu tempo e contemporânea desses movimentos culturais, produto e agente dessas mudanças. Tempo este que é geralmente tratado, de modo equivocado, a partir de uma cronologia - o que é muito bem assinalado por Rivera pelo lugar que uma obra como As meninas de Velazques, do século XVII, tem de paradigmático para autores, psicanalistas e filósofos, assim como para artistas (como Waltércio Caldas), na subversão pósmoderna desse espaço representacional.

Tal reversão do tempo, como a do espaço, cria um outro estatuto ao objeto de arte e ao sujeito, trazendo para o primeiro plano a aproximação com o campo da ética e da política. É, novamente aqui, a relação com o outro, afetado pela criação e pela evanescência do fenômeno estético, que é destacada.

A quarta e última parte do livro, denominada de "Transmissões", inclui quatro ensaios que apresentam análises mais dedicadas ao trabalho de autores específicos. Temos ali as criações de Ernesto Neto, Louise Bourgoise, Milton Machado e Cildo Meireles, trabalhadas em cada um dos capítulos, sempre dialogando com aspectos essenciais da psicanálise. Diferentes aspectos já indicados em capítulos anteriores são retomados, em uma nova volta, em uma nova leitura, demonstrando o potencial criativo ilimitado, ousaríamos dizer, desse diálogo. O texto final, sobre o trabalho de Cildo 


\section{RESENHA DE LIVROS}

Meireles, é um exemplo máximo disso ao trazer para o primeiro plano os reflexos críticos e políticos de operar nesse litoral aberto pela relação entre arte e psicanálise.

Como já salientamos, ao longo de todo o livro a análise se debruça sobre o modo como o espaço clássico das representações, espaço esquadrinhado pela geometria euclidiana e inscrito na percepção pela mimeses antiga ou pela perspectiva moderna, é profundamente alterado pelo campo de experiência proposto pela arte contemporânea e pela psicanálise. Não se trata de uma modificação que diga respeito apenas ao âmbito do especular; é todo o registro do tempo/duração e do espaço/ presença que os atos analítico e artístico redimensionam e desacomodam. A preciosa análise que a autora dedica ao tema da aura beijaminiana, e sua aproximação inusitada com a transitoriedade em Freud, é um dos elementos importantes nesta leitura, desdobrando seu valor como operador do que se passa no espaço/tempo da percepção estética e suas consequências políticas, isto é, na posição de um sujeito entre outros.

Outro aspecto a destacar é a ampla utilização de termos como "sujeito" e "objeto" sem ferir sua origem no vocabulário psicanalítico ou artístico, mas sem nenhum tipo de formalização amarrada que precisa pedir licença aos mestres. A língua e seus vocábulos - significantes - são de todos e de cada um, o que não implica, neste caso, num convite ao exercício da ignorância, mas antes à criatividade erudita, à livre expressão douta. E elas perpassam a leitura de uma gama importante de trabalhos de artistas significativos da cena contemporânea, com destaque para os autores brasileiros, a começar por Lygia Clark e Hélio Oiticica, até os mais atuais como Cildo Meireles, Ernesto Neto, Milton Machado e Waltércio Caldas. Certamente que outros poderiam ter aí também seu lugar. Mais um mérito do livro: nenhuma pretensão de universalidade ou de totalidade. São escolhas feitas pela autora, perpassadas pelo seu gosto pessoal e/ou pelos diálogos contingenciais que foram sendo construídos ao longo da elaboração desses ensaios. A nós, leitores, o papel de testemunhos do profícuo desse debate que, sob a primorosa escrita de Tania Rivera, chega até nossas mãos. A publicação desse livro condiz bem com o que, segundo Cildo Meireles (citado por Rivera), estaria na base da construção de um objeto de arte: uma doação, um generoso gesto da autora no compartilhamento dessas elaborações através desta publicação.

\section{Maria Cristina Poli}

Psicanalista; Professora do Programa de Pós-Graduação em Teoria Psicanalítica e do Doutorado e Mestrado Profissional em Psicanálise Saúde e Sociedade da Universidade Veiga de Almeida (Rio de Janeiro, RJ, Br); Pesquisadora do CNPq e Jovem Cientista do Estado/ FAPERJ.

Rua Augusto Pestana, 146/302

90040-200 Porto Alegre, RS, Brasil

e-mail: mcrispoli@terra.com.br 